\title{
COPIM
}

\section{Combinatorial Books - Gathering Flowers - Part III}

Janneke Adema, Gary Hall, Gabriela Méndez Cota

Published on: Apr 30, 2021

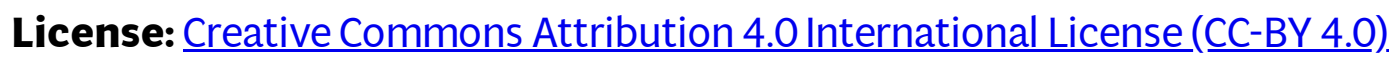


This is the third in a series of blog posts (part I is here and part II is here), which introduce one of the Pilot Projects we are conducting as part of the experimental publishing working group of the COPIM project. In these Pilot Projects, COPIM project members are collaborating with authors and publishers to create three or more experimental books. (For a typology of experimental books, see our previously published research report here). They are also documenting the publishing process along the way-through reflective blog posts such as this, for example. One of COPIM's Pilot Projects is run by Open Humanities Press (OHP) in collaboration with a group of scholars, technologists, and students from the Universidad Iberoamericana Ciudad de México (including Etelvina Bernal Méndez, Sandra Hernández Reyes, Sandra Loyola Guízar, Fernanda Rodríguez González, Yareni Monteón López, Deni Garciamoreno Becerril, Nidia Rosales Moreno, Xóchitl Arteaga Villamil and Carolina Cuevas), led by Dr Gabriela Méndez Cota. The Pilot, titled Combinatorial Books: Gathering Flowers, explores and encourages the revisiting and rewriting of books within the OHP catalogue as a means of generating radical new responses to them. Underneath Méndez Cota describes her and her collaborators experience with the project up to now. 


\section{Ecological Rewriting as Disappropriation}

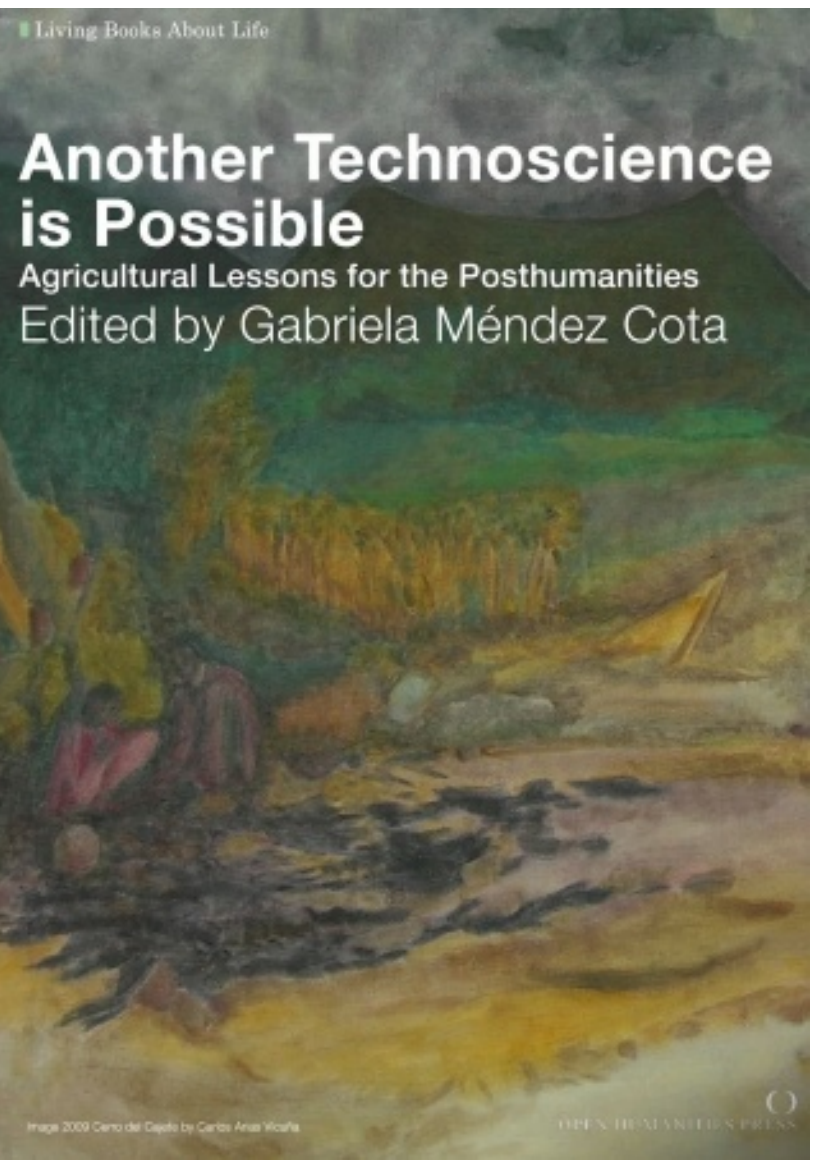

When I accepted the invitation to contribute to the COPIM/OHP Pilot Project, I drew on previous experiences in publishing experiments co-led by OHP, as well as on my own research interests. In 2011, a fragment of my doctoral work on modern representations of agriculture and national identity in Mexico took the provisional form of a speed-edited book for the project Living Books About Life. My subsequent exploration of the OHP series Critical Climate Change in the context of postgraduate teaching and institutional development at $\underline{17}$, Institute of Critical Studies (2016-2017) then became the topic of a volume within the Liquid Book series in Pbworks. Between 2014 and 2016, I reused the concept behind 'living' and 'liquid' publishing as part

of a collective art project around edible weeds, cooking and popular defence of heritage sites in the Mexican city of Cholula, Puebla. All of these experiences gradually shaped my current interest in articulating philosophical thinking of socioenvironmental devastation and extinction, on the one hand, and experimental writing and editing in the spirit of Radical Open Access, on the other hand. I chose The Chernobyl Herbarium: Fragments of an Exploded Consciousness by philosopher Michael Marder and artist Anaïs Tondeur for this 'rewriting' experiment or Pilot Project, because I had been sharing and discussing this work with reading groups in Mexico, and had noticed how well it was received in this particular context, resonating as it does with the grief that the country has experienced due to the multi-faceted and spiralling violence of neoliberal restructuring since around the time of the Chernobyl explosion. And, of course, The Chernobyl Herbarium, which OHP published in 2016 under a CC-BY ShareAlike license, is already an inspiring example of formal experimentation with the book form, a collective 'rewriting' of which would allow me to continue to pursue my 
research interests in a creative register, by paying attention to the material medium from which they evolve: writing, publishing, collaborating.

For the Pilot Project I gathered a rewriting team of former students and colleagues that work with me in the research project Filosofía de la práctica editorial: acceso abierto y diversidad en perspectiva crítica (Universidad Iberoamericana Ciudad de México 2019-2021), and/or who have a research interest in ecological, political and aesthetic issues. My fellow reescritoras ('re-writers') are Etelvina Bernal, Sandra Hernández Reyes, Sandra Loyola Guízar, Fernanda Rodríguez González, Yareni Monteón López, Deni Garciamoreno, Nidia Rosales, Xóchitl Arteaga Villamil and Carolina Cuevas. Our work as a newly formed team involved six months of discussing what 're-writing' is about, why and in what way we would want to do that with The Chernobyl Herbarium. As a way to get us started, I asked my team to make connections between The Chernobyl Herbarium and my prior work on agricultural and ecocultural narratives in Mexico, and specifically on the representations of edible weeds called quelites, so as to collectively decide what kind of 're-writing' we would like to undertake that made sense to us where we are at philosophically, politically and ethically.

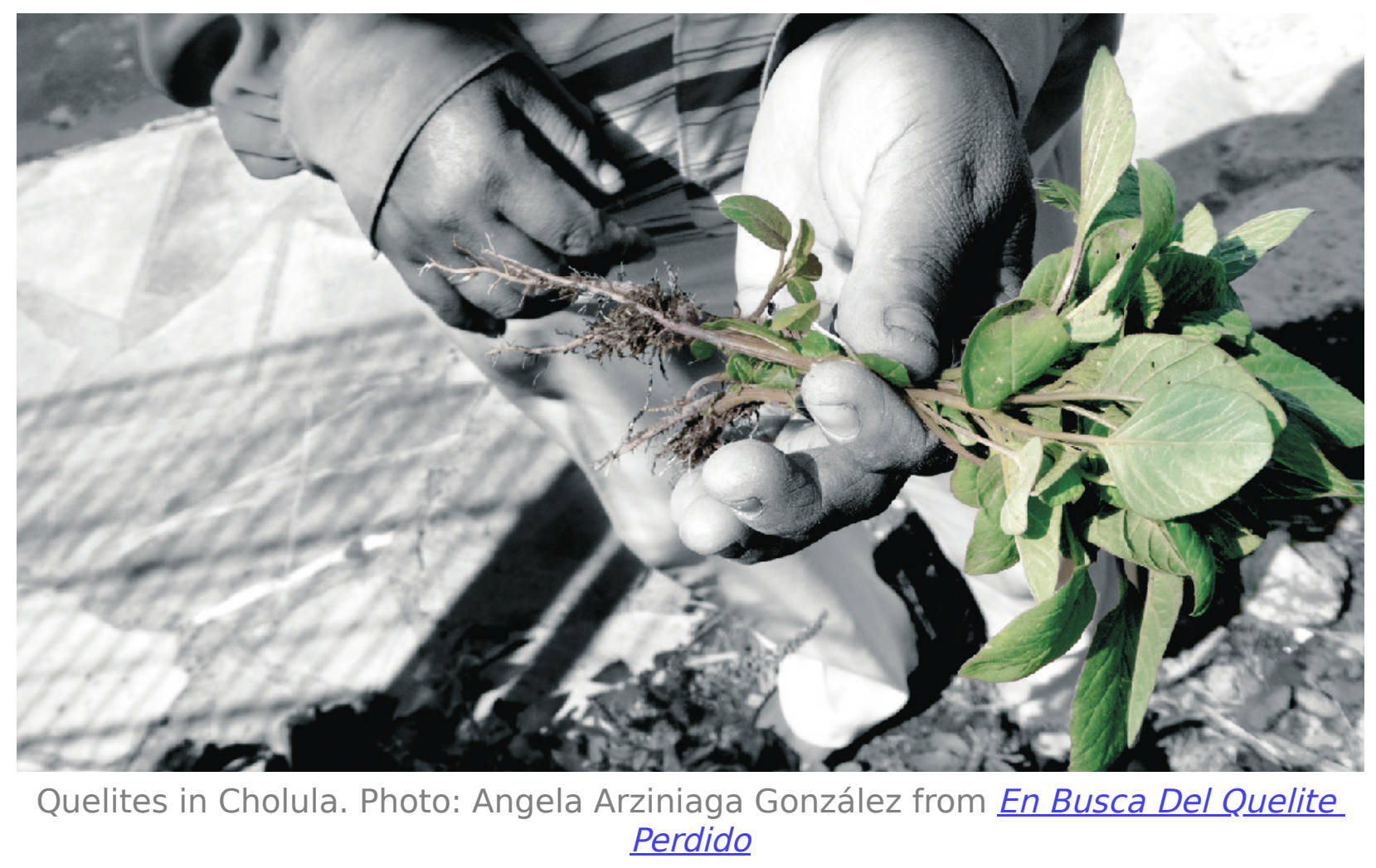


Among the diverse creatures that make up the traditional farming system called milpa, maize has been most visibly deployed in Mexico as a unifying metaphor of national identity. Meanwhile, quelites (from the indigenous language Náhuatl: 'tender edible weeds'), which grow spontaneously at the feet of maize plants, have attracted much less attention in mainstream images and celebrations of Mexican identity. In recent years, however, quelites have emerged alongside rural women in political narratives as ecological representatives calling for more just and sustainable futures for the Mexican nation. In my examination of shifts in the metaphorical use of traditional agriculture - which can be explained sociologically by pointing at various empirical factors such as changing attitudes regarding biocultural diversity, civil resistance to neoliberal globalization, public health concerns, and the growing popularity of green and ethical consumerism in evermore crowded and polluted cities - I tried to go beyond an empirical description of such factors and bring into play a more literary and philosophical analysis of quelite narratives. In a recent book chapter, my 'queering' of such narratives was an attempt to expose their anthropocentric and androcentric tendencies, as well as to open up paths for thinking beyond gendered ethical structures that remain firmly rooted in philosophical modernity. This is where the story of quelites intersects with The Chernobyl Herbarium, and I believe it was crucial to set in motion a conversation about the content and the form of a new book that we could call our own while eschewing the fetishism of authorship, intellectual property, individual genius, originality and so forth.

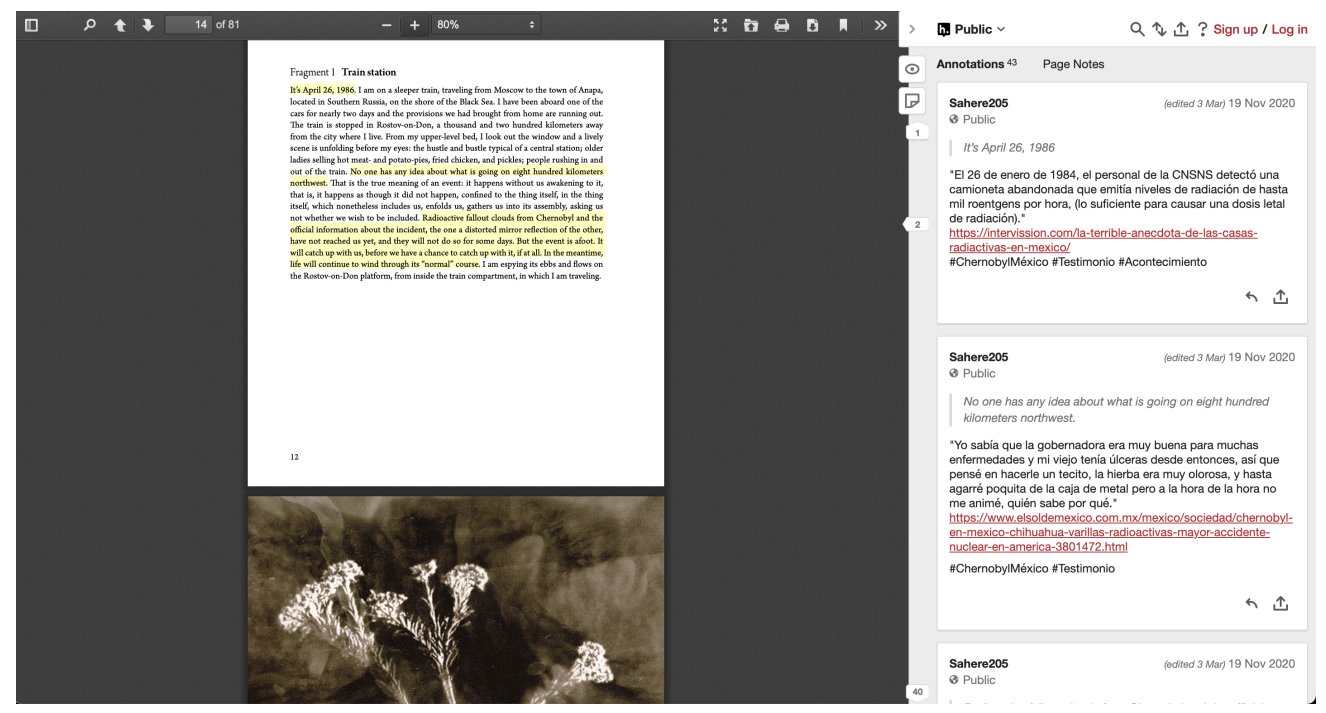

Annotating The Chernobyl Herbarium online with the aid of the Hypothes.is plugin. 
In response to the invitation of 'appropriating' the text of the Chernobyl Herbarium in a way analogous to how many contemporary artists and experimental scholars have done in order to intervene, contest, and disrupt notions of property, authorship, originality, and so forth, our sense of purpose grew out of trying to align our understanding of 're-writing' with the material and historical context in which we set out to do that, and with the vegetal thinking at work in The Chernobyl Herbarium. Since, as Humanities scholars working in traditional academic departments, we don't have a lot of familiarity with editorial design, programming or disruptive digital tools and artistic experiments, we just began to collaboratively annotate the Chernobyl Herbarium online PDF, with the aid of the hypothes.is plugin, and kept a journal of our meetings in a HedgeDoc pad. After more or less systematically tagging the annotations we came up with a potential table of contents that would enable each of us to develop particular sections of the book without losing sight of a general structure or other people's writing process. We decided to work in this way before actually getting to experiment with the technical and formal dimensions of the book because we realised that the 're-writing' project needed a shared narrative and motivation so as to sustain the time and effort that it demands. It would become clear that we would like to 're-write' the Chernobyl Herbarium first of all by leaving it as it is, and yet, at the same time, opening it to time and space.

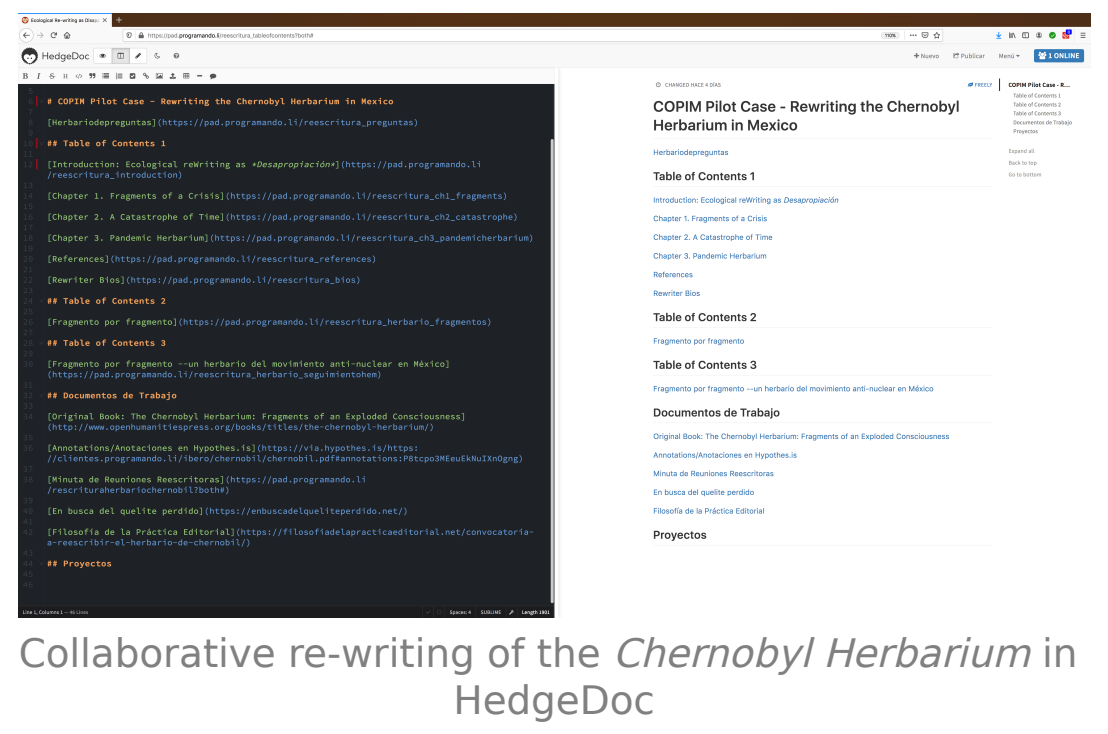

In the Mexican context, experiments with writing, art, and technology have a history that is less tied to academic publishing or avant-garde scholarship than to communitybuilding and grassroots organising around the various manifestations of structural violence (economic inequalities, internal colonialism, ecocidal extractivism, authoritarianism, organised crime, etcetera). Here, an influential notion is $\underline{\text { Cristina }}$ 
Rivera Garza's understanding_of re-writing_as disappropriation, which she elaborated by bringing together Jean-Luc Nancy's reflections on 'literary communism' and Mexican indigenous practices of comunalidad. Re-writing, she says, is not about appropriation, but rather it is about exposing the incomplete, processual nature of any text; it is about making time and taking the time, and it is about relating to others in accountable ways. Beyond Rivera Garza's formulations, we would like to explore ways of becoming accountable for invisible connections between human and non-human aspects of contemporary devastation, and for the scalar conflicts which any ethical or political narrative inevitably inhabits. Our book, which will be written collectively and published in different structures and formats which highlight its processual nature, will elaborate a narrative on Mexico's relation with Chernobyl. The book will explore the little-known history of nuclear power and the anti-nuclear movement experimentally intersected with the history of plant biodiversity (Chapter 1), continue with a theoretical reflection on plant-thinking in Spanish (Chapter 2), and end with a new liquid 'herbarium' that documents socioenvironmental devastation from the standpoint of particular quelites (Chapter 3). In these chapters, The Chernobyl Herbarium and my previous work on quelites will be 're-written' in different ways, through disappropriation as much as appropriation, and above all through collective experimentation, which takes time and labour. 